\title{
ORGANIC FERTILIZER: THE UNDERESTIMATED COMPONENT IN AGRICULTURAL TRANSFORMATION INITIATIVES FOR SUSTAINABLE SMALL HOLDER FARMING IN NIGERIA UKOJE, J.A. ${ }^{1}$ and ${ }^{*}$ YUSUF, R.O. ${ }^{2}$ \\ http://dx.doi.org/10.4314/ejesm.v6i6.10S
}

\begin{abstract}
Received 30th July 2013; accepted 18th November 2013

Emphasis on increase agricultural productivity of small holder rural peasants from the perspective of soil conditioning has been on chemical fertilizer while the impact of the bio-organic input has been neglected. This paper examines this issue through a combination of review of available literature and a micro survey of 120 farmers purposively selected from Sabon-gari local government area of Kaduna state, Nigeria. Using a checklist of questions, data were collected for three farming seasons and simple descriptive techniques were employed in data analysis. The study reveals that acreage among the respondents was very small (2-5 acres mostly) and this has no significant impact on chemical fertilizer utilization. Organic fertilizers used include soil from waste dumpsite, cattle and poultry waste and crop residues. These nonchemical fertilizers are consistently used (>50\%) and the costs are cheaper than the chemical fertilizers though with some drawbacks such as not being readily available in required quantity and longer duration of releasing nutrients required by plants. To maximise overall socioeconomic and environmental benefits of organic fertilizers, the recommendations proffered include developing an integrated multidisciplinary soil fertility restoration that will incorporate farmers' perception into mainstream research; implementing a reward system for farmers and researchers who utilize inorganic fertilizers.
\end{abstract}

Key words: Organic input, environmental remediation, food security, small-holder rural farmers, sustainable agriculture, agricultural transformation.

\section{Introduction}

Peasant farmers are the largest producers of food consumed in Nigeria who should be the major beneficiaries of positive outcome of agricultural transformation initiatives. Particularly a major aspect is fertilizer application because of varying levels of soil degradation and fertility in Nigeria (Margulis et al., 2007). Sustainable agricultural transformation programmes should factor in the peculiar production logic of smallholder farmers alongside ecological and environmental insurances that the transformation can be real and long lasting.

However, cursory examination of food and agriculture enhancement initiatives of successive administrations in Nigeria reveals that there is still a missing link in adequate understanding of sustainable input utilization by small holder rural farmers in Nigeria. Ample literatures abound on the multifaceted issues of chemical fertilizers

Department of Geography, Federal University, Lokoja,

Kogi State, Nigeria

Department of Geography, Ahmadu Bello University,

Zaria, Nigeria

*Corresponding author: royusoba@yahoo.co.uk
(Yusuf, 2007; Margulis et al., 2007; Morris et al., 2006) among others.

Many of these authors examined issues on composition of chemical fertilizers, nature and properties of agrochemicals; growth, productivity, and yield, of crops associated with fertilizer, environmental pollution externalities in chemical fertilizer and so on. Nonetheless, most important focus is on inaccessibility of farmers to chemical fertilizers. According to Gbadegesin et al. (2002), about $70 \%$ of the farmers studied accepted that the use of fertilizer led to increased yield. For about $87 \%$, it led to increased income and for about $38.3 \%$, it led to increased acreage. Very few, if at all have investigated in some detail, alternative organic soil improving input that have become options of choice for small-holder farmers in Nigeria. This is no doubt because of the disposition of scholars to non-conventional issues that doubt conformity to mainstream macro-economic development options favoured by multinational agribusiness proponents and 
researchers. This alternative organic input option in Nigeria's food security programme is the focus of this paper. This paper adopts triangulation approach; combining a systematic content analysis of secondary materials and micro survey of small holder farmers from whom were obtained primary data.

The objectives of the paper are twofold;

- Examine the sources of chemical fertilizer and non chemical options available to small holder farmers, and

- Evaluate the contributions of sustainable organic input to socioeconomic and environmental remediation.

These objectives are to synthesize current knowledge and practice towards improving the food security and agricultural development in Nigeria. Of course the overall goal is human and environmental resource management.

Researches like this have their bases in sustainable agriculture which integrates human socio-economic development with environmental remediation. For instance Essiet and Tundun Wada (1999) discovered that farmers in Kumbotso area of Kano state, Nigeria use tannery sludge, municipal wastes and animal waste to improve soil fertility though the authors cautioned that continuous use of tannery and municipal waste could lead to possible sodicity of the soil with obvious unwanted consequences. Swaminathan et al. (2007) report of extensive study in Tamil Nadu (India) also provides instructive insights in to the economic benefits of bio-inputs.

In Borno state, Nigeria, Kwaghe et al. (2011) reported that farmers re-use agricultural waste comprising crop residues and animal waste whose cost is about $4 \%$ of the farmers' total annual revenue. Similarly Yusuf, Ukoje and Abduraheem (2013) also discussed how farmers use excavation pits for sustainable agricultural practices where the water accumulated in these pits were used for year-round cultivation thereby reducing the socioeconomic costs of sinking borehole for irrigation activities and simultaneously restoring fauna to an otherwise waste land. These works and several others conducted in different parts of the world provide rationale for the present study though at a micro scale.

\section{Literature Review}

It is important to recognize that fertilizer is not panacea for all of the problems that afflict African agriculture and that promoting fertilizer in isolation from other needed actions will have little lasting impact (Morris et al 2007). African land degradation problems can be attributed to many causes, but analysts generally agree that a contributor is failure of most farmers to intensify agricultural production in a manner that maintains soil fertility. For instance, Nigeria is estimated to have lost 57kg/ha/years during the 2002-2004 cropping season and fertilizer use intensity in $1996-2002$ is $5.6 \mathrm{~kg} / \mathrm{ha}$ and percentage increase is $73 \%$.

Past efforts at promoting increase fertilizer use include direct subsidies that reduced the price of fertilizer for farmers; government financed and managed input credit programmes; centralized control of fertilizer procurement and distribution activities and centralized control of key output markets (with the goal of stabilizing prices and linking input and output marked to ensure smoother credit management).

Organic fertilizer when available can, and should be an integral component of soil fertility management strategies but organic fertilizer alone will not be sufficient to support the sustained high productivity and production levels that will be necessary to feed Africa's rapidly growing population. This is due to space -time variability in production and utilization.

Among several problems in African agriculture are disappearing fallows, deforestation and land degradation. Land degradation refers to the temporary or permanent reduction in the product of land and this is attributable to continuous utilization of cultivable land with inadequate soil fertility renewal. Inorganic, mineral, chemical or synthetic fertilizer contains straight single nutrient: nitrogen, phosphorus or potassium and compound or mixed fertilizers contained more than one of these macro nutrients and trace elements while inorganic sources are animal manure, household waste, plant materials 
including crop residues and compost. The two have impact in Nigeria.

According to Margulis, et al. (2006), soils in Nigeria are not highly productive, owing to poor moisture retention capacity and low organic matter. No soil type in Nigeria contributes to high productivity. This is pushing farmers into a fragile equilibrium in which use and conservation are crucial to avert further degradation. Indeed, the 1990 Global Assessment of soil degradation (GLASOD) estimates the 27\% of global land surface had some form of degradation,

In previous years in Nigeria, DFID (2005) undertook a review of annual field surveys which showed a decline in yield of maize in 26 states, cassava in 10 states, millet in 8 states, and rice in 13 states from 1996-2004. Cereals yields have declined between 1980 and 2003, yet this has been accompanied by a decline in fertilizer consumption and erratic fluctuation in accessibility among small-holder rural farmers (Yusuf, 2007) which make them to employ some sustainable agricultural practices.

Bolorunduro and Aribido (2001) reported that sustainable agriculture means that natural ecosystems are enhanced rather than threatened, rural based social structures are strengthened are rather than fragmented and local resources are preferred. The authors recommended soil conservation by farmers, improvement of degraded land and integration of livestock fishery and crop production to facilitate ecological restoration, disease control and solving other agro-related problems. As encapsulated by Shweta and Kumar, (2007) unsustainable agricultural practices include burning of plant residue for their disposal; excessive use of agrochemicals produced from non-renewable sources; disruption of complex soil process by conventional agricultural practices, such as unnecessary tillage, application of unbalanced chemical fertilizers and pesticides to soil; poisoning of food chain due to use of toxic pesticides and, excessive irrigation, leading to soil salination and ground water depletion

Application of organic fertilizers as a component of sustainable agriculture apart from soil mineral provision contribute to soil quality by improving the structure, chemistry and biological level of soil. These shape the overall health of agricultural soils. Another advantage is gradual release of nutrients and reusing soil organic matter content. And because it is based mostly on locally sourced materials with little or no dependence on external inputs, it is one of the eco-supportive infrastructures advocated by Yusuf and Ukoje (2012) for sustainable rural development. A disadvantage of organic matter is that when decomposition is rapid, more nutrients are released but release of soil organic matter on the underhand is favoured by slow decomposition. The decomposition of organic matter operates with moisture and temperature which cannot be controlled hence nutrient may be released when plants do not need them. Also, limited availability of organic matters is characteristic of many regions hence it cannot meet crop nutrient need alone.

The advantages of inorganic fertilizers is that nutrient content is known and they release nutrient quickly became other materials need not to be decomposed. Hence timing of nutrient uptake can be predicted very well. The disadvantages of inorganic fertilizer are high cost and long-term environmental damage which perhaps outweigh the advantages considering the poverty level of Nigerian farmers and the fragility of the farming ecosystem.

Fertilizer utilization in Africa during the $1990 \mathrm{~s}$ is about 1.3 milion tonnes representing less than $1 \%$ of global fertilizer consumption. According to Adesina (2012) fertilizer use per ha in sub-Saharan Africa is the lowest in the world. Also it is always easy to estimate or establish yield increase due to other inputs (agro chemicals, irrigation, mechanization, labour and yield increase due to adoption of modern/improved high yielding varieties) but that of sustainable inputs is usually silent.

The Nigerian agricultural transformation agenda (to grow food, create job and ensure security) can be achieved if the aspect of sustainable input utilization is rigorously pursued. Nigeria's yield per hectare is $20 \%$ to $50 \%$ of that 
obtained in similar developing countries. Hence new policies, institutions and financial structures to drive agricultural sector growth are necessary. Some are deregulation of seed and fertilizer sectors, marketing reforms to structures market, innovative financing for agriculture, and new agricultural investment framework. In this regard e-wallet voucher which is purchase of fertilizer through mobile phones are encouraged. If all these are successfully executed, the problem of environmental degradation from conventional agricultural practices particularly increased fertilizer utilization may prove to have environmental sustainability drawbacks.

For instance experience in Tamil Nadu (Swaminathan et al., 2007) reveals that indiscriminate application of fertilizers has altered the physicochemical properties of the soil, change the biological balance, and altered the soil $\mathrm{pH}$ and structure with detrimental consequences for plant growth. Regrettably, the commonest synthetic fertilizer in the study area, (NPK) (which is socioenvironmentally similar to Nigeria $\}$ is accused of having imbalance plant nutrients. It is against this background that this paper examines the organic input used by farmers in rural settlements of Sabon-gari local government area of Kaduna state, Nigeria.

\section{Materials and Methods}

Based on the objectives, the nature of study is exploratory hence it adopts a small sample to test the underlying assumption that access to chemical fertilizers has been consistently low and smallholder farmers rely on alternative soil conditioner to improve soil fertility and crop yield. The study adopts an exploratory research design approach hence a micro survey was used. A total of 120 farmers were purposively selected form different rural settlements in Sabon-Gari local government area (LGA) of Kaduna state. Sabon Gari LGA is located approximately within latitude $10^{\circ} 90^{\prime}$ and $11^{\circ} 30^{\prime} \mathrm{N}$ and longitudes $7^{\circ} 50$ and $7^{\circ} 70 \mathrm{E}$. The area falls within the northern Kaduna sub-region, with a characteristic savanna vegetation. According to the 2006 census, the population of the area is 286871 (Federal Republic of Nigeria,
2007) over $65 \%$ of which are rural dwellers engaging in different agricultural livelihood options. This makes the selected rural settlements appropriate for the study. Socio-culturally, the indigenous people are Hausa/Fulani.

The six settlements selected from Basawa and Bomo which are the two politically defined rural wards in the LGA include Bomo, Kurmin Bomo, Hayin Liman, Milgoma Basawa, and Dupa Dupa. Owing to the exploratory design of the study (because there were no documented evidences of previous studies of this nature), 20 farmers were each selected from each rural settlement.

Data were analyzed with descriptive statistical methods for ease of interpretation. A checklist of questions was prepared with which farmers were interviewed. This was coupled with observation of cropping pattern of the farmers. The survey was conducted on the farm during the 2012-13 farming season but information were sought on the previous two seasons to establish a trend.

\section{Discussion \\ Socioeconomic Characteristics}

The majority of farmers are not too old as the age range for about $35 \%$ was between 20-30 years while those between $31-40$ years were $22 \%$. Very few were above 60 years. The farmers sampled were males for obvious socio-cultural peculiarities of study location in northern Nigeria setting. Primary and secondary schools were the highest formal educational institutions attended by $21 \%$ and $16 \%$ of respondents respectively. However, all of the Muslims (87\%) had acquired Qur'anic education with some informal training in masonry, carpentry, auto repairs, painting and other artisanal endeavours. As such these artisanal training provides off-season non farm income for the rural peasants. All the respondents use the output for household consumptions with little for sale and their income is quite low as less than $87 \%$ claimed to have a monthly income of less than N15,000.00. About $85 \%$ were married with family size ranging from 6-5 (28\%); 7-10(30\%) $11-14(36 \%)$ respectively. 


\section{Farming characteristics and use of fertilizer}

A fundamental determinant of small holding is size of farm land. Revealed in table 1 is the acreage of respondents and comparative cost of chemical and non chemical fertilizer used.

Table 1 percentage cost fertilizers per average

\begin{tabular}{lllll}
\hline $\begin{array}{l}\text { Farm size } \\
\text { (areas) }\end{array}$ & Frequency & Cost & $\begin{array}{l}\text { Cost of non } \\
\text { chemical } \\
\text { input }\end{array}$ & Total \\
\hline$<2$ & 15 & $24 \%$ & $17 \%$ & $41 \%$ \\
$2-5$ & 38 & $23 \%$ & $28 \%$ & $51 \%$ \\
$6-9$ & 21 & $31 \%$ & $27 \%$ & $58 \%$ \\
$10-13$ & 17 & $45 \%$ & $29 \%$ & $74 \%$ \\
$14-17$ & 20 & $51 \%$ & $37 \%$ & $88 \%$ \\
718 & 9 & $54 \%$ & $32 \%$ & $86 \%$ \\
\hline
\end{tabular}

The result reveals that holding is quite small among the farmer with very few having more than 20 acres. Holding of 2-5 acres is common as represented by $31.7 \%$ of respondents while those with 6-7 acres were barely $17.5 \%$.

An observation is that as acreage increases so also is cost of chemical fertilizer but not progressively. As such there is decline in fertilizer use as farm size increase perhaps because of socioeconomic accessibility to mineral (chemical) fertilizer. However the cost of non-chemical fertilizer output is consistently high $(>50 \%)$ of the total indicating the silent role sustainable input is playing in sustaining peasant farming, hence food security in Nigeria.

This finding is similar to that of Swaminathan et al (2007) that the use of non-synthetic fertilizers has not only increased over the years, but some farmers now cultivate crops without chemical fertilizers relying only on bio-inputs. This has even prompted the assertion that chemical fertilizers are no longer the heroes of the green revolution in India. Table 2 presents the types of crops cultivated by farmers in the present study.
Table 2 Crops cultivated per total output

\begin{tabular}{lll}
\hline Crops & No of respondent & Percentage \\
\hline Maize & 117 & 97.5 \\
Millet & 27 & 22.5 \\
Rice & 52 & 43.3 \\
Guinea corn & 48 & 40 \\
Beans & 44 & 36.7 \\
Vegetables & 98 & 81.7 \\
Groundnut & 46 & 46.7 \\
\hline
\end{tabular}

About $106 \%$ of the respondents practice mixed cropping combining cereals, pulses and vegetables. Maize is commonest which has fast become food and cash crop among the population. Upland rice and guinea corn are also very highly cultivated mostly for food and local exchange. Vegetables like tomato, okro, sesame, pepper etceteras are cultivated by many. Millet is the least cultivated crop because of its decreasing popularity as staple food crop compared to maize and guinea corn

\section{Fertilizer Utilization}

Both organic and inorganic fertilizers are used by farmers. The variation is however in types and quantity. The types of chemical fertilizer used by the farmers include NPK, Urea, and super phosphate fertilizers. All these are generic soil conditioners common in the northern part of Nigeria despite the spatio-temporal variability in soil characteristics. For instance soil types in the study area include ferruginous, ferralitic and mollisols depending on whether they are on upland or wetland (Fadama). Table 3 presents sources of chemical fertilizers among respondents.

Type and use (per fertilizer gross) of non chemical fertilizer vary from respondents due to variation in cropping pattern and cropping systems. The summary is presented in table 4 . Majority of respondents still rely on the market to procure chemical fertilizers. This is because of the guaranteed availability based on economic demand. Farmers group farming association and local government council distribution options were very common and significant during the three consecutive farming seasons examined. 
Table 3 Procurement of Chemical fertilizers

\begin{tabular}{lllllll}
\hline & \multicolumn{7}{c}{ Percent per farming/cropping season } \\
\cline { 2 - 7 } Source & $2010-11$ & $2011-12$ & & $2012-13$ & \\
\hline Local government & 12 & 10 & 15 & 12.5 & 8 & 6.7 \\
Farmers Association & 28 & 23.4 & 13 & 10.8 & 4 & 3.3 \\
Regular market & 67 & 55.8 & 82 & 68.4 & 90 & 75 \\
E- wallet voucher & - & - & - & - & - & 75.8 \\
Nil & 13 & 10.8 & 10 & 8.3 & 11 & 9.7 \\
Total & 120 & 100 & 120 & 100 & 120 & 100 \\
\hline
\end{tabular}

Table 4 Types and percentage use of sustainable non chemical fertilizer

\begin{tabular}{lllllll}
\hline \multirow{2}{*}{ Types } & \multicolumn{7}{c}{ Percentage per gross fertilizer use } \\
\cline { 2 - 7 } & \multicolumn{2}{c}{$2010-11$} & $2011-12$ & & $2012-13$ & \\
\hline Soil refuse dump & 58 & 43.6 & 77 & 45.3 & 74 & 42.1 \\
Cow dung & 19 & 14.3 & 24 & 14.1 & 29 & 16.5 \\
Chicken droppings & 17 & 12.8 & 19 & 11.2 & 22 & 12,5 \\
Crop residue\& grass clippings & 19 & 14.3 & 21 & 12.3 & 24 & 13.6 \\
Domestic waste & 20 & 15 & 29 & 17.1 & 27 & 15.3 \\
Total ** & 133 & 100 & 170 & 100 & 176 & 100 \\
\hline
\end{tabular}

** Multiple choice $>120$

Surprising not, the E-wallet fertilizer procurement of the Nigeria agricultural transformation programme has not made a substantial impact during the 2012-13 farming season. Admittedly, "teething problems" always accompany innovative measures. The hope is that ministry of agriculture and the distribution network would have perfected the distribution channels for the ensuring 2013-14 farming season in northern Nigeria.

Among the non-chemical soil conditioners, soils from refuse dump remains a major ones consistently throughout the period under review. This corroborates the findings of Akpu and Yusuf (2011) that farmers use soil from waste dumpsite for soil fertility because urban waste contains high soil organic materials than that of rural areas. Crop residues and grass clippings are used as well as domestic waste particularly kitchen solid wastes and ashes. This finding is different from that of Kwaghe et al. (2011) where animal waste is the major non-synthetic soil improver because of the obvious differences in population of livestock in Borno and Kaduna states.
Surprisingly none of the farmers mentioned compost manure which is among the popular nonchemical fertilizers abound in literature. For illustration, Yadav and Lourduraj (2007) who described composting as an exothermic process claims that because compost contains plant nutrients in available form, it is not only good for increasing agricultural production but also instrumental in bioremediation and pollution prevention; disease control; erosion control and landscaping, as well as reforestation, wetlands restoration and habitat revitalization. This therefore creates a need for participatory engagement of farmers in practical application of simple but efficient sustainable agricultural practices like composting in Nigeria.

A synthesis of tables 1 and 4 is a pointer to the understated roles of non-chemical fertilizer which have remained high in application, low in cost yet improving crop yield significantly. Although determining the percentage contribution of non-chemical fertilizer to gross yield is outside the scope of this paper, it no doubt means that it contribute to low input, sustainable increase in 


\section{Ethiopian Journal of Environmental Studies and Management Vol. 6 Supplement 2013}

yield. Perhaps soil degradation from continual use chemical fertilizer, have been "silently" mitigated through these non-chemical fertilizers as all the farmers use one of them (Yusuf, 2007). As perceived by farmers the non chemical alternatives are longer lasting and remedy degraded land. This surprisingly is consistent with convectional options of experts (for instance Morris et al, 2007). More categorically in Tamil Nadu and other provinces in India, sustainable bio-fertilizers have become more popular among poor farmers and owing to similar socio-economic characteristics with Nigeria should be adopted.

\section{Conclusion}

Small holder rural peasants are the food growers for Nigerian people. Even though available records persistently indicate that chemical fertilizer consumption has been declining hence food output, the contributions of non-chemical alternatives have been largely over looked. This study though a pilot survey with exploratory perspective, has revealed that farmers in study location derive more than $50 \%$ of soil conditioning input from non chemical options with aggregate cost less than that of chemical fertilizer. The shortcomings limiting widespread research on development and adoption of non chemical fertilizers warrant the following recommendations.

Agricultural scientists, pedologists and soil scientists should collaborate with researchers on rural livelihood options to enhance development of soil improvement adaptive strategies that will not only lead to improve yield but also economic sustainability for rural peasants but also environmental sustainability. The Ministry of agriculture should anchor such multidisciplinary adaptive research for national development by establishing bio-fertilizers production units.

The Nigeria agricultural system despite the evidenced reduced utilization of chemical fertilizer has not failed woefully at least in rural areas where reliance on imported basic food stuff is minimal. This gives a hope for sustainable agricultural input capacity development, hence farmers should be empowered through education and enlightenment on compost development, vermicomposting, nitrogen fixation by plant and other sustainable input utilization techniques. By this a lot of financial resources will be saved and judiciously used by both individual farmers and local, state, and federal government agricultural development units. This is in addition to the unanticipated benefits of integrated solid waste management in rural and urban centres of Nigeria.

To facilitate the spread and adoption of sustainable inputs, a reward system should be created such that researchers and investors who invest time and resources in sustainable input should be assisted by government to fast-track their endeavours. Ministries of Agriculture, Rural Development and Environment should champion this course through research and investment support as appendage to key sectors of the economy for the overall benefit of Nigeria.

The agricultural transformation agenda can be less costly, if development of non-chemical fertilizer options is given a modest attention. Apart from reducing the multifaceted transportation-political-bureaucratic bottlenecks and corruption associated with chemical fertilizer distribution, real rural empowerment and poverty reduction will be achieved. This is the essence of bottom-top, home-grown development with substantial socioeconomic and environmental benefits as already done in India and other developing countries with similar socioeconomic and physical characteristics with Nigeria. This indeed will be sustainable transformation of agriculture for the small-holder rural peasantry who provides foods and fibres for Nigeria.

\section{References}

Adesina, A. (2012), Unlocking the potential of Agriculture in SS Africa Nigerian's transformation Agenda for Agriculture. A paper presented at the symposium on "Ground food" New placed, new technologies at Johns Hopkins University of Advanced international studies.

Akpu, B and Yusuf, O. R. (2011), A Rural-Urban Analysis of the Composition of Waste Dumpsites and their Use for Sustainable Agriculture in Zaria, 
Nigerian Journal of Scientific Research, 9\&10 $119-124$

Bolorunduro, P.I. and Aribido, S.O (2001), Approaches for sustainable integrated Agriculture the savanna zone of Nigeria. Nigerian Journal of Agricultural Extension, 13(2), 50-59. DFID (2005), The sustainability of Economic Growth- Harnessing Nigeria's Renewable Natural Resources for Economic Growth. Processed

Essiet, E.U. and Tundun, Wada, I Y (1999), Amendment of Soil fertility using differing urban solid waste materials in Kumbotso, Kano state. Journal of Social and Management Studies, 6, 5563

Federal Government of Nigeria (2007), Federal Republic of Nigeria, Official Gazette Vol. 94, No 24 Government Printer, Lagos

Gbadegesin, R.A., Adybeton, J.O., Onyibe, L.E., Keki. P.K., Amos, T.T., Yusuf, J.O. and Omeneza, Z.E. (2002), Evaluation of the Extent of Adoption and impact of improved technologies on maize, rice, and cassava production in the North West zone of Nigeria. Nigerian journal of Agriculture Extension, 14(12), 1-12.

Kwaghe, P.V., Gwary, M.M., Abdusalam, R.Y. and Oppong-Yeboah, A. (2011), Economic analysis of Agricultural Waste Management among Farming Households in Jere Local Government of Borno state, Nigeria, Journal of Agriculture and Biological Sciences, 2(6), 193- 198.

Morris, M., Kelly, V.A., Kopicki, J.R. and Byerke, D. (2007), Fertilizer use in African Agriculture lessons learned and hood practice Guideline, Washington D.C The World Bank.

Margulis, S., Pillar, P., Rula, G., and Chee, N. (2006), Nigerian Rapid country Environmental analysis Washington, DC, The World Bank.
Shweta and Kumar, K. (2007) 'Role of organic farming in sustainable agriculture' in Trivedi, P.G. (ed) Organic farming and Mycorrhizae in Agriculture, I.K International Publishing House, Pvt Ltd, New Delhi pp 73-76

Swaminathan, L.P., Jahan Moram, K.R; Sundaravaradhajaran, K.R, Padma Rani, Saravanan S.P and Sundaresan, R. (2007), 'A study of Bio-inputs Usage in Agriculture in Tamil Nadu' in Trivedi, P.G (ed) Organic farming and Mycorrhizae in Agriculture, I.K International Publishing House, Pvt Ltd, New Delhi pp 161187

Yadav, B.K. and Lourduraj, A.C. (2007), 'Composing Technology for Organic farming' in Trivedi, P.G (ed) Organic farming and Mycorrhizae in Agriculture, I.K International Publishing House, Pvt Ltd, New Delhi pp 161187

Yusuf, O.R. (2007), Fertilizer Inaccessibility, Rural Livelihood and Sustainable Agriculture in Kaduna state: A Participatory Appraisal. Journal of Agriculture ,Resources and Development, 6, 37-50

Yusuf, O.R. and Ukoje, J.A. (2012), 'The Imperative of "Eco-supportive" Infrastructure for Sustainable rural livelihood in a changing Climate in Iliya, M.A,Abdulrahim,M.A, Dankani, I.M and Opponkumi, A (eds) Climate Change and Sustainable Development. Proceedings of the $52^{\text {nd }}$ Annual conference of the Association of Nigerian Geographers, (ANG) held at Usuman Danfodiyo University, Sokoto, Yusuf, R.O., Ukoje, J.A. and Abdulraheem, B.H. (2013), Adaptation of Excavation Pits for sustainable Urban Farming and Eco-supportive Infrastructure in Kaduna state, Nigeria, American International Journal of Contemporary Research, 3(2), 33-40. 